\title{
COMENTÁRIOS SOBRE A DISTRIBUIÇÃO GEOGRÁFICA DE HETEROTHALAMUS PSIADIOIDES LESS. (ASTERACEAE: ASTEREAE) E REGISTRO DE UMA NOTÁ VEL DISJUNÇÃO ${ }^{1}$
}

\author{
LEONARDO PAZ DEBLE ${ }^{2}$ JOSÉ NEWTON CARDOSO MARCHIORI ${ }^{3}$ \\ ANABELA SILVEIRA DE OLIVEIRA-DEBLE ${ }^{4}$
}

\section{RESUMO}

É registrada a ocorrência natural de Heterothalamus psiadioides Less. (Asteraceae: Astereae) no topo do Cerro Trindade, município de Santana do Livramento, configurando uma notável disjunção geográfica para a espécie.

Palavras-chave: Asteraceae, Baccharis psiadioides, Fitogeografia, Flora do Rio Grande do Sul, Heterothalamus psiadioides.

\section{ABSTRACT}

[Comments on the geographical distribution of Heterothalamus psiadioides Less. (Asteraceae: Astereae) and a remarkable disjunction record].

The natural occurrence of Heterothalamus psiadioides Less. (Asteraceae: Astereae) on the top of Cerro Trinidad, in the municipality of Santana do Livramento (Rio Grande do Sul, Brazil), is presently recorded, setting a remarkable geographical distribution for this species.

Key words: Asteraceae, Baccharis psiadioides, Heterothalamus psiadioides, Phytogeography, Rio Grande do Sul State flora.

\section{INTRODUÇÃO}

Por ocasião de coletas botânicas nos cerros chatos situados a leste da cidade de Santana do Livramento, na província geomorfológica da Depressão Periférica, comprovou-se a ocorrência natural de Heterothalamus psiadioides Less. (sin.: Baccharis psiadioides (Less.) J. Müller) no topo do Cerro Trindade ( $30^{\circ} 59^{\prime} 11.81^{\prime \prime} \mathrm{S}$, $\left.55^{\circ} 25^{\prime} 24.48^{\prime \prime} \mathrm{O}\right)$, junto à borda da cornija. Este registro, além de ser o ponto mais ocidental até o momento conhecido para a espécie no Rio Grande do Sul, também sinaliza uma notável disjunção, justificando a presente nota fitogeográfica.

1 Recebido em 15-11-2012 e aceito para publicação em 10-12-2012.

2 Dr. Professor do Curso de Ciências da Natureza, UNIPAMPA(Dom Pedrito - RS). deble.biol@gmail.com

3 Engenheiro Florestal, Dr. Professor Titular do Departamento de Ciências Florestais, Universidade Federal de Santa Maria. Bolsista de Produtividade em Pesquisa (CNPq - Brasil).

4 Dra. Professora do Curso de Tecnólogo em Gestão Ambiental, URCAMP (Dom Pedrito - RS).

\section{COMENTÁRIOS}

Composto de três espécies nativas (Deble, 2004), o gênero Heterothalamus Less., de acordo com Rambo (1954), integra o "contingente endêmico" da "flora insular" no Rio Grande do Sul, ou seja, um grupo de espécies e gêneros botânicos encontrados apenas, ou quase exclusivamente, na "região montanhosa" situada ao sul da "linha Gravataí-Jacuí-Ibicuî", bem como no Uruguai, nas serras do sul da província de Buenos Aires e na de Córdoba, no centro da Argentina.

No gênero botânico em questão, Heterothalamus alienus (Spreng.) O. Kuntze e Heterothalamus rupestris Deble, Oliveira \& Marchiori distinguem-se por terem folhas lineares, inteiras ou 1-6-dentadas na metade superior, bem como aquênios 5-costados. A primeira delas, com distribuição mais ampla, ocorre naturalmente nos estados do Rio Grande do Sul e Santa Catarina, bem como no Uruguai e nas províncias argentinas de Córdoba e San Luis, até os limites com Santiago del Estero e La Rioja 
(Deble et al., 2005). Em Santana do Livramento, $H$. alienus foi presentemente encontrada no Cerro Florentina ( $30^{\circ} 54^{\prime} 18.61^{\prime \prime} \mathrm{S}, 55^{\circ} 24^{\prime}$ 26.16" O), havendo registro anterior de sua ocorrência em afloramento basáltico distante cerca de $14 \mathrm{~km}$ a oeste da cidade, à margem da estrada que leva a Quaraí (BR 293). Menos conhecida e com distribuição restrita ao Rio Grande do Sul, Heterothalamus rupestris é espécie endêmica de afloramentos rochosos na Serra do Sudeste (Deble et al., 2004).

Heterothalamus psiadioides Less., por sua vez, separa-se facilmente das duas anteriores por ter folhas oblongas de margem serrada na metade superior e aquênios 6-7-costados. Conhecida pelos nomes de "vassoura" e "alecrim-dafolha-larga", a espécie tem distribuição geográfica restrita, embora abundante nos locais em que se encontra. Mais freqüente na Serra do Sudeste do Rio Grande do Sul (Camaquã, Canguçu, Encruzilhada do Sul, Guaíba, Morro Redondo, Pelotas, Porto Alegre, Santana da Boa Vista, Viamão), H. psiadioides encontra-se, ainda, em pontos altos da Serra Geral, como na borda dos cânions da Fortaleza e Itaimbezinho (Cambará do Sul), no litoral (Torres) e no topo de alguns morros da Depressão Periférica, caso do Morro das Pedras, em São Leopoldo (Deble et al., 2005). No Morro da Polícia, em Porto Alegre, a espécie era tão freqüente que, numa única subida, Rambo (1954) contou mais de "10.000 indivíduos a cerca de 20 metros, de ambos os lados do caminho".

No estado de Santa Catarina, existem exsicatas em herbário provenientes de Garopaba, Imbituba e Laguna, inclusive da restinga litorânea (Deble et al, 2005).

No Uruguai, a espécie é assinalada para os departamentos de Treinta y Tres, Rivera e
Taquarembó (Deble et al., 2005). Para os dois últimos, Brussa \& Grela (2007) referem cornijas de arenito e cerros chatos como ambientes característicos, à semelhança do registrado no Cerro Trindade, em Livramento.

De todo modo, o presente registro de Heterothalamus psiadioides no município de Santana do Livramento amplia, significativamente, a distribuição geográfica da espécie no Rio Grande do Sul e, além de sinalizar o ponto mais ocidental de sua ocorrência no Estado, até o momento conhecido, representa uma disjunção digna de nota, por situar-se a mais de $250 \mathrm{~km}$, em linha reta, da area core da espécie, na Serra do Sudeste.

Material coletado: BRASIL. Rio Grande do Sul, Santana do Livramento, Cerro Trindade, 12 X-2012, L.P. Deble, J.N.C. Marchiori \& A.S. de Oliveira, 14.563 (SMDB).

\section{REFERÊNCIAS BIBLIOGRÁFICAS}

BRUSSA SANTANDER, C.A.; GRELA GONZÁLEZ, I.A. Flora arbórea del Uruguay. Con énfasis en las especies de Rivera y Tacuarembó. Montevideo: COFUSA, 2007. 542 p.

DEBLE, L.P. $O$ gênero Heterothalamus Lessing $e$ táxones afins. Santa Maria: UFSM, 2004. 83 p. Dissertação (Mestrado em Engenharia Florestal) - Universidade Federal de Santa Maria.

DEBLE, L.P.; OLIVEIRA, A.S. de; MARCHIORI, J.N.C. Heterothalamus rupestris, espécie nova de Asteraceae do Rio Grande do Sul. Ciência Florestal, Santa Maria, v. 13, n. 2, p. 1-5, 2003.

DEBLE, L.P.; OLIVEIRA, A.S. de; MARCHIORI, J.N.C. O gênero Heterothalamus Less. e táxones afins. Balduinia, Santa Maria, n. 1, p. 1-20, 2005. RAMBO, B. Análise histórica da flora de Porto Alegre. Sellowia, Itajaí, n. 6, p. 9-111, 1954. 